\title{
Caminhando com a juventude: \\ A comunidade missionária de Emaús em Florianópolis
}

\section{Walking with the youth: The Emmaus Missionary Community in Florianópolis}

\author{
André Camargo Guedes Rodrigues* \\ Michelle Tillmann Biz** \\ Simone Hering de Queiroz Yunes***
}

Recebido: 30/06/19. Aprovado: 02/08/19.

Resumo: De forma crescente, a lgreja vem buscando caminhar de maneira mais próxima à juventude. Neste propósito, o Papa Francisco convocou a XV Assembleia Geral Ordinária do Sínodo dos Bispos, com o tema "os jovens, a fé e o discernimento vocacional". O presente artigo apresenta a pastoral da Comunidade Missionária de Emaús em Florianópolis à luz das reflexões levantadas pelo Sínodo. A partir de uma revisão sobre a lgreja e os jovens, e sobre o papel dos movimentos eclesiais para os jovens na Igreja, é apresentado o Movimento de Emaús, sua atuação na Arquidiocese de Florianópolis e seus desafios para a evangelização da juventude no mundo de hoje.

* Doutor em Engenharia Elétrica (UFSC, Florianópolis, 2004). Especialista em Direito Tributário (UNISUL, Florianópolis, 2007). Bacharel em Engenharia de Controle e Automação (UFSC, Florianópolis, 1998). Secretário do Movimento de Emaús da Arquidiocese de Florianópolis, desde 2018.

E-mail: andrer.rodrigues@gmail.com

** Pós-Doutora em Odontologia (UI, lowa City, 2019). Doutora em Biologia Celular e Tecidual (USP, São Paulo, 2007). Mestre em Odontologia (UFPel, Pelotas, 2001). Graduada em Odontologia (UFSC, Florianópolis, 1998). Professora da Universidade Federal de Santa Catarina, Florianópolis, na área de Histologia. Orientadora de grupo de jovens do Movimento de Emaús da Arquidiocese de Florianópolis, desde 2017. E-mail: michelle.biz@ufsc.br

*** Doutora em Engenharia de Produção (UFSC, Florianópolis, 2006). Mestre em Engenharia de Produção (UFSC, Florianópolis, 1996). Bacharel em Administração (UDESC, Florianópolis, 1994) e em Ciências da Computação (UFSC, Florianópolis, 1992). Professora da Faculdade Cesusc, Florianópolis, na área de Gestão de Pessoas. Vice-presidente do Movimento de Emaús da Arquidiocese de Florianópolis, desde 2016. E-mail: simoneqy@hotmail.com 
Palavras-chave: Juventude. Comunidade Missionária de Emaús. Movimentos eclesiais.

Abstract: Increasingly, the Church has been seeking to move closer to young people. In this regard Pope Francis called the XV Ordinary General Assembly of the Synod of Bishops, with the theme "youth people, faith and vocational discernment". This article presents the pastoral mission of the Missionary Community of Emmaus in Florianopolis, and reflect it in the basis of this Synod. Based on a reflection about the Church and the Youth, and on the role of ecclesial movements for the young in the Church, this article presents the Emmaus Movement in the Archdiocese of Florianopolis and describes its challenges for the evangelization of youth today.

Keywords: Youth. Comunidade Missionária de Emaús. Ecclesial movements.

\section{Introdução}

A vida do cristão é um constante chamado a caminhar. Ao meditarmos os mistérios do Rosário, observamos Maria sempre a caminho. Logo após dizer o "sim" e acolher o Cristo em seu ventre e em sua vida, partiu apressadamente às montanhas ao encontro de sua prima Isabel, pôs-se a caminho de Belém para o nascimento de Jesus, foi à Jerusalém para a apresentação de Jesus no Templo e para a celebração da Páscoa, e retornou a Jerusalém à procura do Filho que havia "perdido". Maria continua a caminhar com o Cristo para ajudá-lo a transformar a água em vinho nas Bodas de Caná, e está presente no caminho que Cristo faz ao anunciar o Reino de Deus. E Maria segue caminhando com o Cristo em sua dolorosa Via Crucis, e finalmente se põe a caminho da Jerusalém Celeste, onde recebe a Coroação de Rainha e Mãe de toda a humanidade.

A exemplo de Maria, cada jovem é chamado a receber o Cristo em sua vida e a caminhar com Ele. E como Cristo no caminho de Emaús, a Igreja é convidada a lançar um olhar amoroso, disponível e atento aos jovens, pôr-se a caminhar com eles, escutar o que têm a dizer, ensinar-lhe as escrituras, oferecer-lhes o Pão Vivo e acompanhá-los na missão. E de fato a Igreja vem buscando aproximar-se mais dos jovens, sendo que no ano de 2018 quis estar ainda mais próxima, quando, na XV Assembleia Geral Ordinária do Sínodo dos Bispos, dedicou-se a escutar e dar respostas a estes jovens em caminhada, no que foi chamado "Sínodo dos Jovens". Assim, a partir da reflexão sobre a Igreja e os jovens e sobre o papel dos movimentos eclesiais para os jovens na Igreja, apresentamos neste artigo o papel do Movimento de Emaús, sua atuação na Arquidio- 
cese de Florianópolis e seus desafios para a evangelização da juventude no mundo de hoje.

\section{A Igreja e os jovens}

O evangelista São Lucas retrata muito bem a necessidade dos discípulos de Emaús em encontrar um sentido para o que haviam presenciado (cf. Lc 24,13-35). Caminhavam em meio à tristeza e frustração, buscando consolo, conversando entre si, quando o Cristo se pôs a caminhar com eles. Assim como o Ressuscitado que percorre o caminho com os discípulos, também a Igreja deseja colocar-se a caminho com os jovens de seu tempo, e, a seu exemplo, acolher, acompanhar e conduzir-lhes à luz do Evangelho.

Na conclusão do Concílio Vaticano II, no ano de 1965, o Papa Paulo VI dirigiu-se carinhosamente aos jovens, incitando-os a buscar o exemplo dos antepassados e já sinalizando para a necessidade do rejuvenescimento da Igreja:

A Igreja, durante quatro anos, tem estado a trabalhar para um rejuvenescimento do seu rosto, para melhor responder à intenção do seu fundador, o grande vivente, o Cristo eternamente jovem. E no termo desta importante «revisão de vida», volta-se para vós. É para vós, os jovens, especialmente para vós, que ela acaba de acender, pelo seu Concílio, uma luz: luz que iluminará o futuro, o vosso futuro. ${ }^{1}$

E assim como prenunciado pelo Papa Paulo VI, na III Conferência Geral do Episcopado da América Latina de Puebla (1979), com o Papa João Paulo II a Igreja abraça os jovens em sua caminhada e apresenta como parte das conclusões da conferência a sua "opção preferencial pelos jovens":

A Igreja confia nos jovens. São para ela sua esperança. A Igreja vê na juventude da América Latina um verdadeiro potencial para o presente e o futuro de sua evangelização. Por ser verdadeira dinamizadora do corpo social e especialmente do corpo eclesial, a Igreja faz uma opção

\footnotetext{
PAULO VI. Mensagem do Santo Padre na conclusão do Concílio Vaticano II. Vaticano, 08 de dezembro de 1965. Disponível em: <w2.vatican.va/content/paul-vi/pt/ speeches/1965/documents/ hf_p-vi_spe_19651208_epilogo-concilio-giovani.html>. Acesso em 21 jun. 2019.
} 
preferencial pelos jovens em vista de sua missão evangelizadora no Continente. $^{2}$

Nos anos que se seguiram houve um processo de amadurecimento neste caminhar com os jovens, até que, animado pelo Espírito Santo, o Papa João Paulo II convocou a I Jornada Mundial da Juventude (JMJ), celebrada no Domingo de Ramos, no ano de 1986, em Roma. Desde então a Jornada vem acontecendo a cada três anos, em média, tendo sido realizada a sua $34^{a}$ edição em 2019 no Panamá, reunindo milhões de jovens dos mais diversos lugares do mundo. Este é um momento de muito proveito para os jovens peregrinos do mundo inteiro, que chegam de coração aberto, vivem momentos de encontro, fraternidade e partilha. Estão sedentos por encontrar o sucessor de Pedro, e são acolhidos e nutridos por suas palavras de esperança mergulhadas na verdade do Evangelho de Jesus Cristo. Vivem nestes dias o júbilo da pertença a uma Igreja viva e voltam para suas casas, como os discípulos de Emaús, em missão de anunciar a boa nova do Ressuscitado.

O Papa Francisco tem marcado seu Pontificado por um olhar muito disponível e atento aos jovens, dedicando sua primeira viagem internacional à Jornada Mundial da Juventude no Rio de Janeiro em julho de 2013, apenas quatro meses após o início do seu Pontificado.

Vim conhecer jovens de todo o mundo, atraidos pelos braços abertos do Cristo Redentor. Eles querem encontrar um refúgio em seu abraço, bem ao lado de seu Coração, para ouvir novamente seu claro e poderoso chamado: "Ide e fazei discípulos entre todas as nações". Cristo abre espaço para eles, pois sabe que energia alguma pode ser mais potente que aquela que se desprende do coração dos jovens quando conquistados pela experiência da sua amizade. [...]. A nossa geração se demonstrará à altura da promessa contida em cada jovem quando souber abrir-lhe espaço. ${ }^{3}$

Neste propósito, o Papa Francisco convocou a XV Assembleia Geral Ordinária do Sínodo dos Bispos, com o tema "os jovens, a fé e o

2 III CONFERÊNCIA GERAL DO EPISCOPADO DA AMÉRICA LATINA DE PUEBLA. Documento final: Documento de Puebla. São Paulo: Paulinas, 1979. n. 1186.

3 FRANCISCO. Discurso do Santo Padre por ocasião da cerimônia de boas-vindas à Jornada Mundial da Juventude. Jardim do Palácio Guanabara, Rio de Janeiro, 22 de julho de 2013. Disponível em: <w2.vatican.va/content/francesco/it/speeches/2013/july/ documents/papa-francesco_20130722_gmg-cerimonia-benvenuto-rio.htm>. Acesso em: 25 maio 2019. 
discernimento vocacional", que aconteceu em outubro de 2018 no Vaticano, após dois anos de profunda escuta a jovens no mundo inteiro, da faixa etária de 16 a 29 anos, e de diferentes contextos e culturas. "Sejamos sinal duma Igreja à escuta e em caminho" ${ }^{4}$ disse o Papa Francisco na abertura do Sínodo. Foi um intenso trabalho de escuta e discernimento entre os participantes do Sínodo e os jovens, trazendo à tona um belo fruto: "a opção que o Espírito nos inspirou através da escuta e do discernimento é caminhar com os jovens, indo ao encontro de todos para lhes testemunhar o amor de Deus"s.

O resultado foi apresentado no documento final formulado em três partes. Na primeira parte (Caminhava com eles) é apresentado o contexto atual onde os jovens estão inseridos, suas mais diversas realidades, desafios e esperanças. Na segunda parte (Eles abriram os olhos) vislumbra-se o papel da juventude no processo de renovação da Igreja, abordando temas como o dom da juventude, o mistério da vocação, a missão de acompanhamento e a arte de discernir. E na terceira parte (Partiram sem demora) apresenta-se a Igreja jovem, trazendo a sinodalidade missionária da Igreja, o caminhar no cotidiano, o renovado ímpeto missionário e a formação integral.

Inspirado pela riqueza das reflexões e diálogos do Sínodo dos Jovens, o Papa Francisco presenteou ainda a Igreja com a Exortação Apostólica Pós-sinodal Christus vivit, para os jovens e para todo o povo de Deus. E o Pontífice inicia com a seguinte exortação: "Cristo vive: é ele a nossa esperança e a mais bela juventude deste mundo! Tudo o que toca torna-se jovem, fica novo, enche-se de vida. Por isso as primeiras palavras, que quero dirigir a cada jovem cristão, são estas: Ele vive e quer-te vivo!"’. A exortação traz, assim, o panorama vislumbrado pelo Sínodo dos jovens, apresentando os jovens à luz do Evangelho, o Cristo jovem, as realidades e desafios dos jovens na atualidade, a palavra de esperança da Igreja que caminha com seus discípulos, bem como o chamado à vocação e ao discernimento. O Papa Francisco finaliza a exortação com um lindo pensamento direcionado aos jovens:

4 FRANCISCO. Discurso do Santo Padre na abertura do Sínodo. Auditório do Sínodo, Vaticano, 3 de outubro de 2018. Disponível em: <w2.vatican.va/content/francesco/ pt/speeches/2018/october/documents/ papa-francesco_20181003_apertura-sinodo. html>. Acesso em: 21 jun. 2019.

5 XV ASSEMBLEIA GERAL ORDINÁRIA DO SÍNODO DOS BISPOS. Documento final: os jovens, a fé e o discernimento vocacional. São Paulo: Paulus, 2019. n. 118. 
Queridos jovens, ficarei feliz vendo-vos correr mais rápido do que os lentos e medrosos. Correi «atraídos por aquele Rosto tão amado, que adoramos na sagrada Eucaristia e reconhecemos na carne do irmão que sofre. O Espírito Santo vos impulsione nesta corrida para a frente. A Igreja precisa do vosso ímpeto, das vossas intuições, da vossa fé. Nós temos necessidade disto! E quando chegardes aonde nós ainda não chegamos, tende a paciência de esperar por nós». ${ }^{6}$

A Igreja precisa do ímpeto dos jovens em seu caminho de evangelização. E é no dia a dia que estes jovens são realmente desafiados e chamados a serem testemunhas do Evangelho de Jesus Cristo, e cumprir seu chamado à santidade no mundo de hoje. Para tanto, os movimentos eclesiais possuem um papel fundamental de acompanhamento da juventude.

\section{O papel dos movimentos eclesiais para os jovens}

A partir do Concílio Vaticano II seguiram-se inúmeras iniciativas para a evangelização dos jovens, tendo destaque os movimentos eclesiais. Estes movimentos, de uma forma geral, nasceram do desejo de muitos cristãos de viverem o Evangelho de Jesus Cristo de forma mais concreta em meio a uma mentalidade secular (individualista, utilitarista, hedonista, tecnocentrista $)^{7}$. E estas iniciativas apresentam grande êxito no âmbito da evangelização dos jovens, uma vez que são, segundo o Papa João Paulo II,

expressões providenciais da nova primavera suscitada pelo Espírito com o Concílio Vaticano II, constituem um anúncio do poder do amor de Deus que, superando divisões e barreiras de todo gênero, renova a face da terra, para construir nela a civilização do amor ${ }^{8}$.

6 FRANCISCO. Exortação Apostólica Pós-Sinodal: Christus vivit, para os jovens e para todo o povo de Deus. São Paulo: Paulus, 2019. n. 299.

7 BORGES NETO, R. S. Os movimentos eclesiais contemporâneos e comunidades novas: características fundamentais. In: Atualidade Teológica, XVI/n. 42 (2012), p. 563-586.

8 JOÃO PAULO II. Homilia do Santo Padre no domingo de pentecostes por ocasião do Congresso Mundial dos Movimentos Eclesiais e das Novas Comunidades. Vaticano, 31 de maio de 1998. Disponível em: <w2.vatican.va/content/john-paul-ii/pt/homilies/1998/ documents/hf_jp-ii_hom_31051998.html>. Acesso em: 21 jun. 2019. 
Um movimento eclesial caracteriza-se exatamente pelo seu caráter "eclesial". Neste sentido, a Exortação Apostólica Pós-sinodal Christifideles laici $i^{9}$ apresenta os critérios de eclesialidade para as agregações laicais, sendo este aspecto a essência destes movimentos. Desta forma, são "eclesiais", porque podem pertencer a estas - e, de fato, pertencem - todas as ordens de pessoas na Igreja, leigos ou religiosos, homens e mulheres, sacerdotes e bispos, crianças e adultos, pessoas de todas as classes sociais, em espírito de comunhão entre as diversas vocações, que no Movimento "realizam a Igreja" na variedade dos seus componentes. Estes movimentos, como relata o então Cardeal Joseph Ratzinger, não podem prescindir da Igreja, mas "nascem normalmente a partir de uma personalidade carismática guia, configuram-se em comunidades concretas que, em força de sua origem, conduzem ao Evangelho na sua inteireza e, sem hesitar, reconhecem na Igreja a razão de sua vida, sem a qual não poderiam existir". ${ }^{10} \mathrm{E}$ eis aqui um importante desafio para os jovens que participam destes movimentos: a consciência desse caráter eclesial, que os leva a serem testemunhas vivas do Evangelho para o mundo em suas atividades cotidianas.

Além disso, é caraterística destes movimentos a presença predominante de leigos, como afirmado pelo Papa João Paulo II no Congresso "Os movimentos eclesiais: comunhão e missão no limiar do terceiro milênio":

O que se quer dizer, hoje, com "movimento"? Uma concreta realidade eclesial com participação predominantemente laical, um itinerário de fé e de testemunho cristão que fundamenta o próprio método pedagógico sobre um carisma claro doado à pessoa do fundador em circunstâncias e formas determinadas. ${ }^{11}$

A alavanca de evangelização dentro de cada movimento encontra-se no carisma proposto e inspirado pelo Espírito Santo, proporcionando

9 JOÃO PAULO II. Exortação Apostólica Pós-Sinodal Christifideles laici. 1988. Disponível em: <w2.vatican.va/content/john-paul-ii/pt/apost_exhortations/documents/ hf_jp-ii_exh_30121988_christifideles-laici.html>. Acesso em: 21 jun. 2019.

10 RATZINGER, J. I Movimenti ecclesiali e la loro collocazione teológica. Congresso Mundial de Movimentos Eclesiais. Roma, 27-29 maio 1998, p. 16. Disponível em: $<$ www.mopal.org/it/form/MovEsp/MovEsp.pdf>. Acesso em: 21 jun. 2019.

11 JOÃO PAULO II. Mensagem do Santo Padre aos participantes do congresso mundial dos movimentos eclesiais. Vaticano, 27 de maio de 1998. Disponível em: $<$ http://www.vatican.va/roman_curia/pontifical_councils/laity/documents/rc_pc_laity_doc_27051998_movements-mes-hf_po.html>. Acesso em: 21 jun. 2019. 
aos jovens a experiência concreta do Cristo vivo, que desperta em cada jovem a alegria genuína de ser cristão e a necessidade fundamental de pertencer à Igreja, de viver a vida sacramental. E nesta caminhada, a comunidade se fortalece e se torna madura, crescendo conduzida pela Palavra de Deus, e caminhando na prática conjunta da caridade, fraternidade, oração e serviço. Quem vive o carisma destes movimentos é invariavelmente inspirado pelo Espírito Santo a evangelizar. E de fato, o Papa João Paulo II percebia nestes movimentos uma oportunidade única para a Igreja:

Como é grande, hoje, a necessidade de personalidades cristãs amadurecidas, conscientes da própria identidade batismal, da própria vocação e missão na Igreja e no mundo! E eis, então, os movimentos e as novas comunidades eclesiais: eles são a resposta, suscitada pelo Espírito Santo, a este dramático desafio do final de milênio. Vós sois esta resposta providencial. ${ }^{12}$

É em meio a estes movimentos eclesiais que muitos jovens reencontram o sentido do seu Batismo e de uma vida em Cristo; o verdadeiro significado do ser discípulo e caminhar com o Mestre. Um movimento eclesial organizado favorece, a partir de seu carisma particular enquanto comunidade eclesial, "uma fecunda e ordenada participação [...] na comunhão e missão da Igreja". ${ }^{13}$ Além disso, na medida em que dão espaço para uma vivência de fé profunda e coerente, os movimentos proporcionam para muitos jovens um ambiente fértil no suscitar de sua vocação, e não raro o despertar para a vocação sacerdotal e religiosa.

12 JOÃO PAULO II. Vigília de oração presidida pelo Santo Padre durante o encontro dos movimentos eclesiais e das novas comunidades. Vaticano, 30 de maio de 1998. Disponível em: <w2.vatican.va/content/john-paul-ii/pt/speeches/1998/may/documents/ hf_jp-ii_spe_19980530_riflessioni.html>. Acesso em: 21 jun. 2019.

13 CONGREGAÇÃO PARA A DOUTRINA DA FÉ. Carta luvenescit Ecclesia sobre a relação entre dons hierárquicos e carismáticos para a vida e a missão da Igreja. 15 de maio de 2016. Disponível em: <press.vatican.va/content/dam/salastampa/it/fuori-bollettino/pdf/ PO\%20IUVENESCIT\%20ECCLESIA_Portugues.pdf>. Acesso em: 30 maio 2019 . 


\section{O Movimento de Emaús da Arquidiocese de Florianópolis}

\subsection{O Movimento de Emaús e o curso de valores humanos e cristãos}

O Movimento de Emaús é um movimento eclesial para jovens leigos organizado em vinte e cinco secretariados locais ${ }^{14}$ de seis diferentes unidades da federação (DF, MG, RJ, RS, SC, SP), com o suporte de cinco secretariados regionais ${ }^{15}$, acompanhados por um secretariado nacional que dirige e administra o Instituto das Comunidades Missionárias de Emaús (ICME), sua denominação oficial ${ }^{16}$. Foi fundado por Monsenhor Benedito Mário Calazans, Diretor Espiritual Nacional até 2007, sob o suporte do Arcebispo de São Paulo, Dom Agnelo Rossi, a partir dos Encontros da Juventude iniciados em 1968, recebendo a denominação de Movimento de Emaús em 1972.

Sua premissa fundamental é o anúncio apostólico, mediante a oferta regular de Cursos de Valores Humanos e Cristãos, ou simplesmente Cursos de Emaús, a jovens que possam ${ }^{17}$ : i) "voltar às suas comunidades de origem, onde através da Pastoral Diocesana darão testemunho, executarão serviços cristãos e crescerão espiritual e apostolicamente a fé”; e/ou ii) ser Missionários de Emaús, que "se estabelecerão na Comunidade de Emaús, como caminho de santificação e prestação direta de serviços no movimento".

Embora seja uma organização nacional, os secretariados locais do Movimento de Emaús dispõem de peculiaridades resultantes de sua história particular e de sua relação com a (Arqui)diocese à qual estão

14 Bagé, Brasília, Brusque, Cachoeira do Sul, Caxias do Sul, Cruz Alta, Florianópolis, Frederico Westphalen, Itapetininga, Itapeva, Joinville, Juiz de Fora, Jundiaí, Lavras, Mariana, Osório, Pelotas, Porto Alegre, Rio Grande, Santa Maria, Santo Ângelo, São João Del-Rei, São Paulo, Sorocaba e Valença.

15 MOVIMENTO DE EMAÚS. Secretariados Regionais. Não Paginado. Disponível em: $<w w w . e m a u s . o r g . b r / n a c i o n a l / e s t r u t u r a / s e c r e t a r i a d o s-r e g i o n a i s />$. Acesso em: 21 jun. 2019.

16 MOVIMENTO DE EMAÚS. Secretariado Nacional. Não Paginado. Disponível em: $<$ www.emaus.org.br/nacional/estrutura/secretariado-nacional/>. Acesso em: 21 jun. 2019.

17 MOVIMENTO DE EMAÚS. Histórico. Não Paginado. Disponível em: <www.emaus. org.br/nacional/o-movimento/historico/>. Acesso em: 21 jun. 2019. 
vinculados. Por outro lado, todos eles promovem cursos de Emaús muito similares, com pequenas diferenças entre si.

Um aspecto marcante sobre os cursos de Emaús é seu rigor pedagógico, que contam com uma sequência estrita e bem definida de atividades que se seguem por três dias em regime de clausura. Estas atividades objetivam alavancar a reflexão pessoal e em comunidade a partir de temas relacionados aos valores humanos e cristãos que emergem do Evangelho. O curso de Emaús oferece ao jovem que dele participa a oportunidade para vivenciar uma forte experiência pessoal e em comunidade a partir de uma revisão de vida à luz do Evangelho, propiciando um verdadeiro encontro com o Cristo, uma vez que "a primeira condição para o discernimento vocacional no Espírito é uma autêntica experiência de fé no Cristo morto e ressuscitado"18. A força desta experiência é também resultante do fato de que o curso é voltado exclusivamente ao público feminino ou masculino e o programa do curso não é divulgado nem previamente conhecido por seus participantes. O curso é organizado em sete fases e a orientação de seus três dias em torno das três virtudes teologais, na seguinte ordem: caridade, fé e esperança. As fases e os dias têm atividades e objetivos muito bem definidos, e estes vinculam-se diretamente à caminhada dos discípulos de Emaús (Lucas 21, 13-35), de acordo com o proposto no Sínodo dos Jovens:

Abrir-se à escuta da voz do Espírito exige disposições interiores precisas: a primeira é a atenção do coração, favorecida por um silêncio e um despojamento alcançado pela ascese. Igualmente fundamentais são: a consciência, a autoaceitação e o arrependimento, unidos à disponibilidade de colocar ordem na própria vida, abandonando tudo aquilo que venha a servir de obstáculo, como também de recuperar a liberdade interior necessária para tomar decisões guiadas unicamente pelo Espirito Santo. ${ }^{19}$

Cada curso dispõe de uma equipe de trabalho específica, composta por jovens e adultos com participação ativa no Movimento, além do seu Diretor Espiritual. A equipe deve participar de três ciclos de formação, duas reuniões preparatórias para o curso e uma Missa de Envio pela comunidade. Essa equipe recebe o suporte de duas equipes permanentes: equipe de apoio, operacional, e de oblação, de suporte espiritual. A equipe do

18 XV ASSEMBLEIA GERAL ORDINÁRIA DO SÍNODO DOS BISPOS, 2019, n. 62.

19 XV ASSEMBLEIA GERAL ORDINÁRIA DO SÍNODO DOS BISPOS, 2019, n. 111. 
curso coloca-se como instrumento do Cristo na Caminhada de Emaús, ao passo que os discípulos de Emaús são representados pelos(as) cursistas.

\subsection{A comunidade missionária de Emaús em Florianópolis}

A comunidade missionária de Emaús em Florianópolis está integrada à Arquidiocese desde $1974^{20}$, quando, em 15 de agosto de 1974, por iniciativa de Monsenhor Francisco de Sales Bianchini, iniciou-se o primeiro curso masculino de Emaús na Casa de Retiros do Morro das Pedras (atualmente Vila Fátima) ${ }^{21}$. Desde então, até junho de 2019, foram concluídos 197 Cursos de Emaús na Arquidiocese de Florianópolis, sendo 93 masculinos e 104 femininos, com uma participação total de 9.813 jovens, a grande maioria na faixa etária entre 18 e 30 anos.

Uma distinção desta comunidade em relação à proposta original do Secretariado Nacional, também presente em algumas outras comunidades de Emaús, é a organização de grupos de jovens acompanhados por adulto ou casal orientador, uma vez que "para realizar um verdadeiro caminho de amadurecimento, os jovens precisam de adultos investidos de autoridade" 22 . Há, atualmente, treze grupos de jovens na comunidade em Florianópolis, além de doze grupos de casais formados por membros da comunidade com o Sacramento do Matrimônio, acompanhados por um presbítero. Os grupos objetivam aprofundar a experiência dos três dias do curso de Emaús em vivência de formação e missão denominada quarto-dia.

Os grupos de jovens proporcionam uma dimensão intermediária à proposta original de Emaús, segmentada entre jovens que retornam às comunidades de origem e jovens que permanecem para manter os cursos de Emaús. Deixa-se de manter estrutura voltada apenas para a difusão da experiência pastoral particular do curso de Emaús, para ter-se uma comunidade eclesial mais orgânica, em conformidade à proposta do Sínodo dos Jovens:

20 MOVIMENTO DE EMAÚS EM FLORIANÓPOLIS. O que é?. Não Paginado. Disponível em: <www.emausfloripa.com/o-que-eacute.html>. Acesso em: 21 jun. 2019.

21 Foram Diretores Espirituais da comunidade de Emaús em Florianópolis: Monsenhor Francisco de Sales Bianchini (1974-2006); Padre Carlos Rogério Groh (2006-2008); Padre Vitor Galdino Feller (a partir de 2009). 
Em muitos contextos, existem grupos de jovens muito ativos na evangelização de seus coetâneos por meio de um claro testemunho de vida, em linguagem acessível, e a capacidade de estabelecer relações genuínas de amizade. Esse apostolado nos permite levar o Evangelho a pessoas que dificilmente seriam alcançadas pela pastoral dos jovens, além de contribuir para o amadurecimento da fé daqueles que se comprometem com esse apostolado, que deve, portanto, ser apreciado, apoiado, acompanhado com sabedoria e integrado na vida das comunidades. ${ }^{23}$

Além dos cursos e dos grupos, "os jovens participam da liturgia da missa, tendo especial predileção pelo ministério do canto. Promovem diversas outras ações no campo social, na catequese, no crescimento espiritual que objetivam ajudar especialmente na formação de uma sociedade mais justa e humana" ${ }^{24}$. Assim, o Movimento de Emaús em Florianópolis é comunidade eclesial de leigos com propósito missionário e de formação para a juventude. Em outras palavras, o carisma do Movimento de Emaús em Florianópolis é a evangelização da juventude, expressada em seus objetivos estatutários ${ }^{25}$ :

a) dar aos jovens sólida formação humana, doutrinal e apostólica (Puebla n. 794);

b) dar-lhes um espirito crítico face às estruturas econômicas, políticas e sociais;

c) prepará-los para descobrir, com iniciativa e audácia, novos caminhos para a ação evangelizadora da Igreja;

d) incutir nos jovens um sério compromisso com a promoção da Justiça e do Bem-comum, sempre iluminados pela fé e guiados pelo Evangelho e pela Doutrina Social da Igreja, ao mesmo tempo em que orientados pela inteligência e pela aptidão para uma ação eficaz e perseverante: "Para o cristão, não basta a denúncia das injustiças, pede-se-lhe que seja verdadeiramente testemunha e agente da justiça" (João Paulo II - Puebla n. 793);

e) conscientizá-los de que são "homens de Igreja no coração do mundo e homens do mundo no coração da Igreja" (Puebla n. 786);

f) conscientizá-los de que o leigo deverá buscar e promover o bem-comum: na defesa da dignidade e dos inalienáveis direitos do homem; na proteção dos mais fracos e necessitados; na construção da paz, da

23 XV ASSEMBLEIA GERAL ORDINÁRIA DO SÍNODO DOS BISPOS, 2019, n. 56.

24 MENEZES, R. R. Vem e segue-me: Monsenhor Francisco de Sales Bianchini. Florianópolis, 2008.

25 MOVIMENTO DE EMAÚS EM FLORIANÓPOLIS. Estatuto. Cartório de Registro Civil, Títulos e Documentos e Pessoas Jurídicas, Florianópolis, 4 de agosto de 2018. p. 1-2. 
liberdade, e da justiça; e na criação de estruturas mais justas e fraternas (Puebla n. 792).

Sendo assim, nos seus 45 anos de caminhada, a Comunidade traz consigo inúmeros exemplos de jovens que, a partir de uma profunda experiência de conversão no curso de Emaús e de uma intensa participação no grupo de jovem do Movimento, reforçaram ou assumiram vivência de evangelização e de santificação. Em muitos casos, a Comunidade propiciou também a descoberta da vocação particular.

O detalhamento do carisma da Comunidade Missionária de Emaús em Florianópolis evidencia uma conexão com perspectivas eclesiais fundamentais em direção ao mundo. Entretanto, a vivência do carisma, em que se busca a evangelização da juventude no mundo, traz diversos desafios a serem enfrentados atualmente pela comunidade. E para que este enfrentamento seja bem feito, são necessárias a inspiração no Espírito Santo e a comunhão eclesial, tendo como referência basilar, além do próprio Evangelho, os estudos da Igreja Católica sobre a Juventude, que já trazem elementos fundamentais sobre o papel esperado pela juventude no mundo à luz do Evangelho.

\subsection{Os desafios da Comunidade de Emaús em Florianópolis}

Atendendo à exortação do Papa Francisco de que sejamos uma Igreja atenta aos sinais dos tempos e de que "as comunidades realizem com respeito e com seriedade um exame de sua própria realidade juvenil mais próxima, para poder discernir os caminhos pastorais mais adequados"26, o Secretariado Nacional do Emaús propôs, no início de 2019, uma grande reflexão nos diversos secretariados locais acerca do Documento Final do Sínodo dos Jovens. Assim, lançou, em junho de 2019, uma pesquisa para conhecer a fundo o perfil do jovem do Emaús, com questões que vão desde a formação acadêmica e o serviço pastoral até perguntas que atingem o contexto em que o jovem está inserido, como a castidade e a política. A partir destas reflexões e pesquisas, e a exemplo do Sínodo dos Jovens, será realizado em julho de 2019 o XIII Encontro do Conselho Nacional de Emaús (ECNE), que envolverá representantes jovens e adultos de todos os secretariados. Pretende-se,

26 FRANCISCO. 2019, n. 103. 
como resultado, uma maior compreensão do jovem que está inserido nas Comunidades de Emaús, conforme as particularidades regionais, e a partir daí, a construção de linhas de ação pastoral.

Com base nas reflexões já realizadas, podem-se destacar alguns desafios que se apresentam na atualidade para a Comunidade de Emaús em Florianópolis:

- Atrair mais jovens para evangelização através dos Cursos de Valores Humanos e Cristãos, tendo em vista a diminuição progressiva do número de cursistas. Até o ano de 2004, cerca de 250 jovens faziam o curso anualmente, e a partir de então, a participação anual média reduziu para cerca de 170 cursistas. O número de cursos anuais, que chegou a sete no ano de 1979, e variou de cinco a seis nos anos subsequentes, foi reduzido para quatro cursos (dois femininos e dois masculinos) a partir de 2005, permanecendo neste patamar até os dias de hoje. O desafio está não apenas em atingir os jovens que abracem os princípios de vida baseados nos valores humanos e cristãos, mas também em alcançar jovens sem sólida formação religiosa, mas que apresentam forte vocação espiritual diante do mundo secular. Conforme apontado no Sínodo dos Jovens, "o Evangelho nos pede para ousar e isso desejamos fazer sem presunção e sem proselitismo, testemunhando o amor do Senhor, com mãos estendidas a todos os jovens do mundo". ${ }^{27}$

- Desenvolver lideranças jovens com maior comprometimento e participação na vida sacramental e nas atividades pastorais de suas comunidades e paróquias, buscando com que o jovem viva os sacramentos e marque a diferença dos valores humanos e cristãos em relação às propostas consumistas e pansexualistas do mundo e seus deuses, e se torne evangelizador de outros jovens, numa prática permanente de "Igreja em saída".

- Desenvolver lideranças jovens com maior engajamento, atuação e protagonismo no Movimento, tendo em vista a dificuldade crescente de participação de jovens nas atividades do Movimento e a diminuição do tempo de permanência nos grupos. É um grande desafio manter a perseverança dos jovens no mundo secular, repleto de distrações e afetado

$\overline{27}$ XV ASSEMBLEIA GERAL ORDINÁRIA DO SÍNODO DOS BISPOS, 2019, n. 171. 
pela cultura do individualismo, isolamento, hedonismo e imediatismo. Maior ainda é o desafio de ajudá-los a assumir o protagonismo no Movimento, tendo em vista que "a paixão pela busca da verdade, a admiração diante da beleza do Senhor, a capacidade de partilhar e a alegria do anúncio ainda estão vivos nos corações de muitos jovens que hoje são membros vivos da Igreja. Portanto, não se trata de fazer algo 'por eles', mas de viver em comunhão 'com eles". ${ }^{28}$

- Preparar-se para atender jovens em situação de vulnerabilidade, doença e dor, uma vez que com mais frequência chegam ao curso e aos grupos, jovens com diversas formas de "sofrimento psíquico, depressão, doença mental e distúrbios alimentares, associados a sentimentos de profunda infelicidade ou à incapacidade de encontrar um lugar na sociedade". ${ }^{29}$ Percebe-se a necessidade de uma melhor formação para acolher os jovens nestas situações, além do apoio das famílias.

- Acompanhar, discernir e integrar a fragilidade ${ }^{30}$ nos cursos e nos grupos, tendo em vista a crescente procura de jovens, e também adultos, em situações chamadas "irregulares", como pessoas que contraíram apenas matrimônio civil, ou que simplesmente convivem, ou são divorciadas ou ainda vivem em segunda união, buscando um "discernimento pastoral cheio de amor misericordioso, que se inclina para compreender, perdoar, acompanhar, esperar e, sobretudo, integrar $[. .$.$] aqueles que vivem nas mais variadas periferias$ existenciais". ${ }^{31}$

A estes desafios em destaque somam-se muitos outros, que serão apresentados e discutidos à luz do Espírito Santo no ECNE, que se realizará em julho, e para os quais se buscarão respostas e orientações para o caminho pastoral do Movimento de Emaús.

\footnotetext{
28 XV ASSEMBLEIA GERAL ORDINÁRIA DO SÍNODO DOS BISPOS, 2019, n. 116.

29 XV ASSEMBLEIA GERAL ORDINÁRIA DO SÍNODO DOS BISPOS. 2019, n. 43.

30 FRANCISCO. Exortação Apostólica Amoris Laetitia: sobre o amor na família. São Paulo: Paulus, 2017. n. 291.

31 FRANCISCO. 2017, n. 312.
} 


\section{Considerações finais}

O Documento final do Sínodo sobre a Juventude tem como fio condutor a passagem do Evangelho de Lucas sobre os discípulos de Emaús: "reconhecemos no episódio dos discípulos de Emaús um texto paradigmático para compreender a missão eclesial em relação às gerações mais jovens" 32 . Esta mesma inspiração teve Monsenhor Calazans ao fundar o Movimento de Emaús e conceber um Curso de Valores Humanos e Cristãos voltado à evangelização dos jovens.

Nestes 45 anos de caminhada da Comunidade Missionária de Emaús em Florianópolis, vários têm sido os desafios que se apresentam no caminho, mas sobretudo muitos têm sido os jovens, e também adultos, a fazer um encontro profundo com o Cristo, a sentir o coração arder, a fazer a Ele o convite: "Fica conosco, Senhor!", a repartir o Pão da Vida e a colocar-se em Missão. A experiência da Comunidade Missionária de Emaús em Florianópolis demonstra que a espiritualidade vivida dentro dos movimentos eclesiais impulsiona os jovens de hoje a buscarem, continuamente, o caminho de santidade, vivendo concretamente o Evangelho nas realidades do mundo em que estão inseridos.

O Caminho de Emaús é o caminho que Maria e que o próprio Cristo percorreram e que cada jovem é chamado a percorrer. Cada pessoa possui o desejo de repousar o coração no Amor de Deus, e é na juventude que este desejo se torna presente de forma intensa e que as perguntas sobre $o$ sentido da vida e sobre o caminho da felicidade buscam incessante resposta. Cada jovem traz dentro de si um coração de discípulo que deseja ardentemente sentar-se à mesa com o Cristo na aldeia de Emaús. Como Igreja, temos que nos colocar em movimento e tornar reais aos jovens este caminho e esta aldeia em que o Cristo se faz presente.

\section{Referências Bibliográficas}

BORGES NETO, R. S. Os movimentos eclesiais contemporâneos e comunidades novas: características fundamentais. In: Atualidade Teológica, XVI/n. 42 (2012), p. 563-586.

CONGREGAÇÃO PARA A DOUTRINA DA FÉ. Carta Iuvenescit Ecclesia aos Bispos da Igreja Católica: sobre a relação entre dons hierárqui-

32 XV ASSEMBLEIA GERAL ORDINÁRIA DO SÍNODO DOS BISPOS, 2019, n. 4. 
cos e carismáticos para a vida e a missão da Igreja. Vaticano, 15 de maio de 2016. Disponível em: <press.vatican.va/content/dam/salastampa/it/ fuori-bollettino/pdf/PO\%20IUVENESCIT\%20ECCLESIA_Portugues. pdf $>$. Acesso em: 30 maio 2019.

FRANCISCO. Discurso do Santo Padre por ocasião da cerimônia de boas-vindas à Jornada Mundial da Juventude. Jardim do Palácio Guanabara, Rio de Janeiro, 22 de julho de 2013. Disponível em: <w2. vatican.va/content/francesco/it/speeches/2013/july/documents/papa-francesco_20130722_gmg-cerimonia-benvenuto-rio.html >.Acesso em: 25 maio 2019.

. Exortação Apostólica Amoris Laetitia: sobre o amor na família. São Paulo: Paulus, 2017.

. Discurso do Santo Padre na abertura do Sínodo. Auditório do Sínodo, Vaticano, 3 de outubro de 2018. Disponível em: <w2.vatican. $\mathrm{va} /$ content/francesco/pt/speeches/2018/october/documents/papa-francesco_20181003_apertura-sinodo.html >. Acesso em: 21 jun. 2019.

. Exortação Apostólica Pós-Sinodal: Christus vivit, para os jovens e para todo o povo de Deus. São Paulo: Paulus, 2019, p. 116. Disponível em: <w2.vatican.va/content/francesco/pt/events/event.dir.html/content/ vaticanevents/pt/2019/4/2/christus-vivit.html>. Acesso em: 21 jun. 2019.

III CONFERÊNCIA GERAL DO EPISCOPADO DAAMÉRICA LATINA DE PUEBLA. Documento final: Documento de Puebla. São Paulo: Paulinas, 1979. Disponível em: < portal.pucminas.br/imagedb/documento/DOC_DSC_NOME_ARQUI20130906182452.pdf>.

JOÃO PAULO II. Exortação Apostólica Pós-Sinodal Christifideles laici. 1988. Disponível em: <w2.vatican.va/content/john-paul-ii/pt/ apost_exhortations/documents/hf_jp-ii_exh_30121988_christifideles-laici.html>. Acesso em: 21 jun. 2019.

- Mensagem do Santo Padre aos participantes do congresso mundial dos movimentos eclesiais. Vaticano, 27 de maio de 1998. Disponível em: <www.vatican.va/roman_curia/pontifical_councils/laity/ documents/rc_pc_laity_doc_27051998_movements-mes-hf_po.html>. Acesso em: 21 jun. 2019.

. Vigília de oração presidida pelo Santo Padre durante o encontro dos movimentos eclesiais e das novas comunidades. Vaticano, 30 de maio de 1998. Disponível em: <w2.vatican.va/content/john-paul-ii/ 
pt/speeches/1998/may/documents/hf_jp-ii_spe_19980530_riflessioni. html>. Acesso em: 21 jun. 2019.

JOÃO PAULO II. Homilia do Santo Padre no domingo de pentecostes por ocasião do Congresso Mundial dos Movimentos Eclesiais e das Novas Comunidades. Vaticano, 31 de maio de 1998. Disponível em: $<$ w2.vatican.va/content/john-paul-ii/pt/homilies/1998/documents/hf_jp-ii_hom_31051998.html>. Acesso em: 21 jun. 2019.

MENEZES, R. R. Vem e segue-me: Monsenhor Francisco de Sales Bianchini. Florianópolis: 2008.

MOVIMENTO DE EMAÚS. Histórico. Não Paginado. Disponível em: $<$ www.emaus.org.br/nacional/o-movimento/historico/>. Acesso em: 21 jun. 2019.

. Secretariado Nacional. Não Paginado. Disponível em: <www. emaus.org.br/nacional/estrutura/secretariado-nacional/>. Acesso em: 21 jun. 2019.

. Secretariados Regionais. Não Paginado. Disponível em: <www. emaus.org.br/nacional/estrutura/secretariados-regionais/>. Acesso em: 21 jun. 2019.

. O que é?. Não Paginado. Disponível em: <www.emausfloripa. com/o-que-eacute.html>. Acesso em: 21 jun. 2019.

MOVIMENTO DE EMAÚS EM FLORIANÓPOLIS. Estatuto. Cartório de Registro Civil, Títulos e Documentos e Pessoas Jurídicas, Florianópolis, 4 de agosto de 2018 .

PAULO VI. Mensagem do Santo Padre na conclusão do Concílio Vaticano II. Vaticano, 08 de dezembro de 1965. Disponível em: <w2.vatican. va/content/paul-vi/pt/speeches/1965/documents/hf p-vi_spe_19651208 epilogo-concilio-giovani.html>. Acesso em: 21 jun. 2019.

RATZINGER, J. I Movimenti ecclesiali e la loro collocazione teológica. Congresso Mundial de Movimentos Eclesiais. 18 páginas. Roma, 27-29 maio 1998. Disponível em: <www.mopal.org/it/form/MovEsp/MovEsp. pdf>. Acesso em: 21 jun. 2019.

XV ASSEMBLEIA GERAL ORDINÁRIA DO SÍNODO DOS BISPOS. Documento final. Os jovens, a fé e o discernimento vocacional. São Paulo: Paulus, 2019. 